\title{
CHARACTERISTICS OF POST-NATAL PAKISTANI WOMEN WITH CHRONIC APICAL PERIODONITITIS
}

\author{
Hina Shah ${ }^{1}$, Nighat Nisar², Sofia Butt ${ }^{3}$, Arshad Hassan ${ }^{4}$ \\ 1Department of Community and Preventive Dentistry, Sindh Institute of Oral Health Sciences, Jinnah Sindh Medical \\ University, Karachi - Pakistan \\ 2,Department of Community Medicine, Dow University of Health Sciences, Karachi - Pakistan \\ 3,Department of Gynaecology, Dow University of Health Sciences, Karachi - Pakistan \\ 4,Department of Operative Dentistry, Dow University of Health Sciences, Karachi - Pakistan
}

\begin{abstract}
Objective: The purpose of this research was to identify the characteristics of post-natal Pakistani women with Chronic Apical Periodontitis (CAP).

Material and methods: This cross-sectional study was conducted among 150 post-natal women who suffered from CAP at the Gynaecology ward, Unit III, Civil Hospital Karachi (CHK). Data were collected from women who delivered babies on the day of data collection at the Gynae ward CHK and satisfied the criteria to be included in the study. Principal Investigator assessed radiographs for the presence of CAP.
\end{abstract}

Results: Mean age of participants was $26.61 \pm 4.83$. Majority $104(69.3 \%)$ were multigravida while 46 (30. \%) were primigravida. The mean gestational period in weeks was $36.16 \pm 2.31$. The majority of the participants 115 (76.7\%) had CAP in a single tooth, $32(21.3 \%)$ had in 2 teeth and $3(2 \%)$ had CAP in 3 teeth. Periapical index (PAI) score was significantly associated with the birth type (normal term and preterm). Baby weight significantly differed between PAI scores.

Conclusion: Results of this study indicate most of the study women were illiterate and belong to a low-income families. There was a higher percentage of multigravida and most of the deliveries were normal vaginal. CAP in a single tooth was found among the majority of the study women.

Keywords: Chronic Apical Periodontitis, Post natal, periapical index

This article may be cited as: Shah $\mathrm{H}$, Nisar N, Butt S, Hassan A. Characteristics of post-natal Pakistani women with Chronic Apical Periodonititis. J Med Sci 2020 October;28(4):313-317

\section{INTRODUCTION}

Chronic Apical Periodontitis (CAP) has been reported to be a prevalent disease especially in adults ${ }^{1,2}$. Numerous researches showed that $24-61 \%$ of adults suffer from Chronic Apical Periodontitis ${ }^{3}$. Premature parturition difficulties are the key reason for death for children less than 5 years, resulting in more than 1 million mortality in 2015 alone. In Pakistan, approximately 17-24\% of deliveries are low birth weight, regardless of time of delivery.

\section{Correspondence}

Dr. Hina Shah

Assistant Professor

Department of Community and Preventive Dentistry

Sindh Institute of Oral Health Sciences Jinnah Sindh

Medical University, Karachi - Pakistan

Email: dr.hina95@yahoo.com

Cell: +92-315-8750511

Date received: $17-07-2020$

Date revised: $15-11-2020$

Date accepted: $12-12-2020$
Correspondingly, a Pakistani study reported that more than $80 \%$ of the new-borns weighted from 2100 to 2500 grams ${ }^{4}$.There are various disabilities in children that are linked with preterm birth which consist of a motor and cognitive deficiency like Attention Deficit Hyperactivity Disorder (ADHD) ${ }^{5}$. Literature shows that out of 13 million children who survive, three percent develop moderate to severe impairments of the neurons with an additional 4.4\% develops mild neurodevelopmental disabilities and around 77 million Disability Adjusted Life Years (DALYs) ${ }^{6}$. When compared to babies born full-term, these disabilities are two to threefolds more usual in preterm babies ${ }^{7}$.

Researches accomplished in the field of periodontal medicine advocate that during pregnancy the periodontitis is potentially a marker for LBWPT ${ }^{8,9}$, and regardless of considerable differences between the endodontic pathology and periodontitis, there are distinct resemblances, like the constant relation with anaerobic gram-negative 
Characteristics Of Post-Natal Pakistani Women With Chronic Apical Periodonititis.

microorganisms and the discharge of increased levels of cytokines ${ }^{10}$. Moreover, oral cavity infections may result in the existence of bacterial products like Lipopolysaccharide or endotoxin from gram-negative microorganisms and encourage the production of cytokines, with TNF-a, IL 1- and IL-6, escalating the release of prostaglandins that may result in LBWPT $^{9}$. Chronic Apical Periodontitis (CAP) is a condition in which an apical portion of the root of tooth is inflamed chronically which is commonly not painful. Newly, Chronic Apical Periodontitis (CAP) has been identified as one of the potential risk factors associated with LBWPT births ${ }^{11-13}$. Epidemiological researches exhibited the burden of CAP around the globe such as Spain, Cana$\mathrm{da}$, Japan, Turkey and USA ${ }^{14}$ that a substantial number of adults are facing this situation. The burden varies from 7 to $20 \%{ }^{15}$. The burden of CAP especially with bone lesions (mild- severe) is greater among general population particularly females, though the findings are from shorter scale studies $^{16-19}$.

Endodontics and periapical status are significant indicators that can estimate tooth survival and further requirements for dental treatment ${ }^{20}$. But research on the prevalence of CAP has not been conducted in the Pakistani population specifically among post-natal women so the exact burden of CAP, which is generally an asymptomatic condition, is still not known in post-natal Pakistani women. Given its relationship with low birth weight babies and premature birth, it is substantial to measure its magnitude. The lack of an adequate number of evidence warrants research on the topic especially in settings like Pakistan where both the burden of CAP and incidence of LBWPT births is high. The purpose of the current research study was to identify the characteristics of post-natal Pakistani women with Chronic Apical Periodontitis.

\section{MATERIAL AND METHODS}

This cross-sectional study was conducted at the Gynaecology ward, Unit III Civil Hospital Karachi (CHK), from September 2016 to November 2017. A total of 150 post-natal women who had Chronic Apical Periodontitis (CAP) were recruited in this study. Data were collected from women who delivered babies on that day at the Gynae ward CHK. Mothers with age group 18-49 years with healthy gums and periodontium, singleton pregnancy, delivering either through $\mathrm{C}$-section or normal vaginal delivery were included in this study. Informed consent was also obtained from all study participants. As noted previously, women with following conditions, such as gestational diabetes, preterm birth, twin pregnancy, pre-eclampsia, eclampsia, post-delivery BMI less than $18.5 \mathrm{Kg} / \mathrm{m} 2$, using antibiotics in last 4 weeks, have less than 18 teeth, are smokers, used alcohol and illegal drugs were excluded. Participants were examined for the Periodontitis by the examiner and excluded if had unhealthy gums and periodontium (Periodontitis).

CAP was labelled using Peri Apical Index (PAI) by Orstavik for the assessment of radiographs which consist of scores ranged from 1 (healthy) through 5 (severe Periodontitis). ${ }^{21}$ Both cases and controls underwent radiography between 24-48 hours of delivery. Women having scores of 3 or more will be labelled as having CAP. Periapical radiographs of the suspected teeth (untreated caries, unsatisfactory treated and necrosed teeth) were taken for the diagnosis of CAP (except third molars) within 2448 hours of delivery. Radiographs were assessed for the presence of CAP by the principal investigator.

Institutional Review Board of Dow University of Health Sciences granted ethical approval letter No: (IRB730/DUHS/Approval/2016/243) to the study. For the sake of the privacy of patients, confidentiality and anonymity were made sure. The sample size was calculated through the statistical software (Sample size determination in health studies WHO). By using the prevalence of CAP as $54.5 \%$ among post-natal women with $8 \%$ Confidence limits and a 95\% confidence interval. ${ }^{22}$ The calculated required sample size was 149 , however, data were taken from 150 post-natal women.

After the baby's birth and mother shifted to the room, data had been collected through questionnaires to record the information regarding demographic, pregnancy history, and new-borns data. Periapical radiographs of the suspected teeth (unsatisfactory treated, untreated caries, and necrosed teeth) were obtained for CAP diagnosis (other than third molars) within two days of delivery. Principal investigator examined radiographs for the presence of CAP. SPSS version 21.0 was used to enter and analyzed the study data. For all categorical variables frequencies and percentages were mentioned (education, age, family size, income, gravida, parity, CAP, BMI and number of teeth having (AP) and mean and the standard deviation was estimated for the quantitative variable such as age. The association between CAP and participants' characteristics were obtained with the level of significance as $5 \%$.

\section{RESULTS}

Table 1 depicts the demographic characteristics of participants. The mean age of the study women was $26.61 \pm 4.83$. Among all participants 63 (42\%) were unable to read or write, 53 (35.3\%) were primary, 28 (18.7\%) were matric and $6(4 \%)$ were intermediate educated. There were 137 (91.3\%) participants who had monthly income less than or equal 15,000 rupees and $13(8.7 \%)$ had monthly 
income more than 15,000 rupees. The majority of the participants had less than or equal to 6 members in the family while $53(35.3 \%)$ had more than 6 family members.

Table 2 shows the gestational characteristics of enrolled women of study. Majority 104 (69.3\%) were multigravida while $46(30 \%)$ were primigravida. The mean gestational period in weeks was $36.16 \pm 2.31$. The average height and weight of participating mothers were $157.24 \pm 8.86 \mathrm{~cm}$ and $55.26 \pm 5.45 \mathrm{~kg}$ respectively. The average BMI of participants was $22.42 \pm 2.35 \mathrm{~kg} / \mathrm{m} 2$. The majority of women $135(90 \%)$ had spontaneous vaginal delivery while $15(10 \%)$ had a caesarean section. There were $72(48 \%)$ participants who had low birth weight infants and $75(50 \%)$ were baby boys. The mean birth weight of infants was $2459.33 \pm 593.93$ grams. Table 3 presented the distribution of the number of teeth having CAP and PAI scores among study participants. The majority of the participants 115 (76.7\%) had CAP in single teeth, 32 (21.3\%) participants had2 teeth, and $3(2 \%)$ had3 teeth affected by CAP. About 97 (64.7\%) postnatal women had mild CAP (score 3), 45 (30\%) had moderate (score 4) while 8 (5.3\%) had severe CAP (score 5). Table 4 depicts the association of PAI (Mild/Moderate/Severe) score with the type of birth, mode of delivery, number of teeth having CAP, and baby weight. Chi-square test confirmed that there PAI score was significantly associated with the type of birth (normal term and pre-term). Whereas the mode of delivery and number of teeth having CAP did not show any significance with PAI scores. Two-sample independent t-test exhibited that baby weight significantly differed between PAI scores (P-value $<0.05)$.

Table 1: Characteristics of post-natal Pakistani women with Chronic Apical Periodontitis (CAP)

\begin{tabular}{|c|c|c|}
\hline Characteristics & Frequency (n) & Percentage (\%) \\
\hline Age & $26.61 \pm 4.83$ \\
\hline \multicolumn{3}{|c|}{ Education } \\
\hline Unable to read or write & 63 & 42.0 \\
\hline Primary & 53 & 35.3 \\
\hline Matric & 28 & 18.7 \\
\hline Intermediate & 06 & 04.0 \\
\hline $\begin{array}{c}\text { Monthly household } \\
\text { income in Rupees }\end{array}$ & $12526.66 \pm 2813.43$ \\
\hline \multicolumn{3}{|c|}{ Income } \\
\hline$\leq 15,000$ Rupees & 137 & 91.3 \\
\hline$>15,000$ Rupees & 13 & 8.7 \\
\hline No of family members & Family size \\
\hline \multicolumn{2}{|c|}{$6.34 \pm 1.03$} \\
\hline$\leq 6$ members & 97 & 64.7 \\
\hline > 6 member & 53 & 35.3 \\
\hline
\end{tabular}

\section{DISCUSSION}

The study was conducted to assess the characteristics of Chronic Apical Periodontitis (CAP) among post-natal Pakistani women. The evaluation of CAP was dependent on standard periapical radiographs, scored by two distinct assessors therefore there were minimal chances of examiner under-reporting because periapical radiographs give fine and minute details. The PAI index can also be used on panoramic radiographs, where an increased rate of CAP is present. ${ }^{22,23}$ Irrespective of this usual usage of the index, research reported that it can underestimate the occurrence of CAP as compared to periapical radiographs ${ }^{11}$. In our study, periapical radiographs are the investigation of choice compared to panoramic examination due to the better visualization of the periapi-

Table 2: Gestational characteristics of post-natal Pakistani women with Chronic Apical Periodontitis (CAP)

\begin{tabular}{|c|c|c|}
\hline \multicolumn{3}{|c|}{ Gravida } \\
\hline Characteristics & 46 & 30.7 \\
\hline Primrigravida & 104 & 69.3 \\
\hline Multigravida & $2.31 \pm 36.16$ \\
\hline $\begin{array}{c}\text { Gestational period in } \\
\text { weeks }\end{array}$ & \multicolumn{2}{|c|}{$8.86 \pm 157.24$} \\
\hline Mother height (cm) & $2.35 \pm 22.42$ \\
\hline Mother weight (Kg) & 135 \\
\hline BMl (kg/m2) & 15 & 90.0 \\
\hline \multicolumn{2}{|c|}{ Mode of delivery } \\
\hline Normal vaginal delivery & 70.0 \\
\hline Caesarean & 75 & 50.0 \\
\hline \multicolumn{2}{|c|}{ Baby gender } \\
\hline Male & 75 & 50.0 \\
\hline Female & 78 & 52.0 \\
\hline Low birth weight \\
\hline No & 72 & 48.0 \\
\hline Yes & $593.93 \pm 2459.33$ \\
\hline Baby weight (grams) & Percentage (\%) \\
\hline
\end{tabular}

Table 3: Gestational characteristics of post-natal Pakistani women with Chronic Apical Periodontitis (CAP)

\begin{tabular}{|c|c|c|}
\hline No of teeth having CAP & Frequency $(\mathbf{n})$ & Percentage(\%) \\
\hline 1 toothhaving CAP & 115 & 76.7 \\
\hline 2 teeth having CAP & 32 & 21.3 \\
\hline 3 teeth having CAP & 3 & 2.0 \\
\hline \multicolumn{2}{|c|}{ PAI Score } \\
\hline $\begin{array}{c}\text { 3 Mild CAP (Change } \\
\text { in bone structure with } \\
\text { mineral loss) }\end{array}$ & 97 & 64.7 \\
\hline $\begin{array}{c}4 \text { Moderate CAP (well } \\
\text { defined radiolucent area) }\end{array}$ & 45 & 30.0 \\
\hline $\begin{array}{c}5 \text { Severe CAP } \\
\text { (exacerbating features) }\end{array}$ & 8 & 5.3 \\
\hline
\end{tabular}


Characteristics Of Post-Natal Pakistani Women With Chronic Apical Periodonititis.

Table 4: Association of PAI Score with term birth, mode of delivery, Baby weight and No. of Teeth having CAP

\begin{tabular}{|c|c|c|c|c|c|}
\hline & \multicolumn{4}{|c|}{ PAI Score } & \multirow[t]{3}{*}{ P-value } \\
\hline & \multicolumn{2}{|c|}{ Mild CAP } & \multicolumn{2}{|c|}{ Moderate/ Severe CAP } & \\
\hline & Frequency(n) & Percentage (\%) & Frequency(n) & Percentage (\%) & \\
\hline \multicolumn{5}{|c|}{ Type of birth } & \\
\hline Normal term birth & 57 & 73.10 & 21 & 26.90 & \multirow[t]{2}{*}{0.025} \\
\hline Preterm birth & 40 & 55.60 & 32 & 44.40 & \\
\hline \multicolumn{5}{|l|}{ Mode of delivery } & \\
\hline Normal vaginal delivery & 88 & 65.20 & 47 & 34.80 & \multirow[t]{2}{*}{0.609} \\
\hline Caesarean & 9 & 60.00 & 6 & 40.00 & \\
\hline \multicolumn{5}{|l|}{ No of Teeth having CAP } & \\
\hline One tooth & 77 & 67.00 & 38 & 33.00 & \multirow{2}{*}{0.288} \\
\hline$>1$ teeth & 20 & 57.10 & 15 & 42.90 & \\
\hline Baby weight (grams) & $585.44 \pm 2529.89$ & & $593.09 \pm 2330.18$ & & 0.045 \\
\hline
\end{tabular}

cal anatomy. Moreover, this radiography procedure creates the best precision to break down apical structures of all dental gathering, specifically in the anterior district of mouth, where the radiopaque projection of the spine confuses the examination of this district ${ }^{11}$.

Interpretation of radiographs, either panoramic or periapical or in combination, is the only method that can be employed in an epidemiological study while assessing CAP. Some research studies also incorporate clinical examination and or interview ${ }^{24}$.

Most of the women participants (42\%) in our study were unable to read and write, two-third of study women belonged to a low-income family and had a family size up to six members.

Our study showed that most of the women were illiterate. The reason behind this finding might be lack of education which leads to lower nutritional state and lack of knowledge on oral care, malpractice, and prenatal care increases the risk of low birth weight neonates. Small family size ( $\leq 6$ members) was found to be prevalent in our study, this result was found to be consistent with the results of studies conducted in Germany and Sri Lanka ${ }^{25}$, ${ }^{26}$. Our study showed that the majority of the women 104 $(69.3 \%)$ were multigravida and the mean gestational period was $36.6 \pm 2.31$ weeks. The majority of the deliveries (90\%) was a normal vaginal delivery. Sex of the baby was evenly distributed. Furthermore, there were $48 \%$ of babies born with low birth weight. In our study, 3/4th of participants had CAP in single teeth whereas nearly two-third patients had PAI score 3 (mild CAP). PAI score was significantly associated with the type of birth (normal term and preterm). Furthermore, baby weight significantly differed between PAI scores. These findings were consistent with the study 8 that showed preterm birth and baby weight were significantly associated with periodontitis.

\section{CONCLUSION}

The results of this study indicate most of the study women were illiterate and belong to a low-income family. There was a higher percentage of multigravida and most of the deliveries were normal vaginal. CAP in a single tooth was found among the majority of the study women.

\section{REFERENCES}

1. Kabak Y, Abbott PV. Prevalence of apical periodontitis and the quality of endodontic treatment in an adult Belarusian population. Int endodontic . 2005 Apr;38(4):23845.

2. Kayahan MB, Malkondu Ö, Canpolat C, Kaptan F, Bayırlı G, Kazazoglu E. Periapical health related to the type of coronal restorations and quality of root canal fillings in a Turkish subpopulation. Oral Surgery, Oral Medicine, Oral Pathology, Oral Radiio, and Endodont. 2008;105(1):e58-e62.

3. López-López J, Jané-Salas E, Estrugo-Devesa A, Castellanos-Cosano L, Martín-González J, Velasco-Ortega E, et al. Frequency and distribution of root-filled teeth and apical periodontitis in an adult population of Barcelona, Spain. Inter Dental J. 2012;62(1):40-6.

4. Baig SA, Khan N, Baqai T, Fatima A, Karim SA, Aziz S. Preterm birth and its associated risk factors. A study at tertiary care hospitals of Karachi, Pakistan. JPMA. 2013;63(3):414-8.

5. Sucksdorff M, Lehtonen L, Chudal R, Suominen A, Joelsson P, Gissler M, et al. Preterm birth and poor fetal growth as risk factors of attention-deficit/hyperactivity disorder. Pediatrics. 2015;136(3):e599-e608.

6. Blencowe H, Lee AC, Cousens S, Bahalim A, Narwal R, Zhong $\mathrm{N}$, et al. Preterm birth-associated neurodevelopmental impairment estimates at regional and global levels for 2010. Pediatr Res. 2013;74(S1):17-34.

7. Torchin H, Ancel P, Jarreau P, Goffinet F. [Epidemiology of preterm birth: Prevalence, recent trends, short-and longterm outcomes]. J Gynecol Obstet Biol Reprod (Paris). 2015;44(8):723-31.

8. Kumar A, Basra M, Begum N, Rani V, Prasad S, Lamba AK, et al. Association of maternal periodontal health 
with adverse pregnancy outcome. J Obs and Gynae Research. 2013;39(1):40-5.

9. Ide M, Papapanou PN. Epidemiology of association between maternal periodontal disease and adverse pregnancy outcomes-systematic review. J Clin Periodontol. 2013;40(s14):181-94.

10. Elsalhy M, Azizieh F, Raghupathy R. Cytokines as diagnostic markers of pulpal inflammation. Inter endodontic J. 2013;46(6):573-80.

11. Leal ASM, de Oliveira AEF, Brito LMO, Lopes FF, Rodrigues VP, Lima KF, et al. Association between chronic apical periodontitis and low-birth-weight preterm births. J Endod. 2015;41(3):353-7.

12. Khalighinejad N, Aminoshariae A, Kulild JC, Sahly K, Mickel A. Association of end-stage renal disease with radiographically and clinically diagnosed apical periodontitis: a hospital-based study. J Endod. 2017;43(9):143841.

13. Farooq I, Khabeer A, Al-Jandan B. Effect of Various Predisposing Factors on Host Defence Mechanisms Triggering Oral Infections-A Comprehensive Review. J Med Sci. 2019;27(4):376-81.

14. Pak JG, Fayazi S, White SN. Prevalence of periapical radiolucency and root canal treatment: a systematic review of cross-sectional studies. J Endod. 2012;38(9):1170-6.

15. Melo L, Ferreira I, Lacet G, Braga AC, Pina-Vaz I. Apical periodontitis and oral status in patients with different systemic conditions and smoking habits in Portuguese population. Endodoncia. 2017;35:10-22.

16. Costa TH, de Figueiredo Neto JA, de Oliveira AE, Lopes e Maia Mde F, de Almeida AL. Association between chronic apical periodontitis and coronary artery disease. J Endod. 2014;40(2):164-7.

17. Dovigi EA, Kwok EY, Eversole LR, Dovigi AJ. A retrospective study of 51,781 adult oral and maxillofacial biopsies. J Am Dent Assoc. 2016;147(3):170-6.

18. Rashmi N, Galhotra V, Goel P, Rajguru JP, Jha SK, Kulkarni K. Assessment of C-reactive Proteins, Cytokines, and Plasma Protein Levels in Hypertensive Patients with Apical Periodontitis. J Contemp Dent Pract. 2017;18(6):51621.

19. Saini HR, Sangwan P, Sangwan A. Pain following foraminal enlargement in mandibular molars with necrosis and apical periodontitis: A randomized controlled trial. Int Endod J. 2016;49(12):1116-23.

20. Ahmed I, Ali R, Mudawi A. Prevalence of apical periodontitis and frequency of root-filled teeth in an adult Sudanese population. Clinic and experi dent research. 2017;3(4):142-7.
21. Ørstavik D, Kerekes K, Eriksen HM. The periapical index: a scoring system for radiographic assessment of apical periodontitis. Dental Traumatology. 1986 Feb;2(1):20-34.

22. Leal AS, de Oliveira AE, Brito LM, Lopes FF, Rodrigues VP, Lima KF, de Araújo Martins IC. Association between chronic apical periodontitis and low-birth-weight preterm births. J endod. 2015 Mar 1;41(3):353-7.

23. Khalighinejad N, Aminoshariae A, Kulild JC, Mickel A. Apical periodontitis, a predictor variable for preeclampsia: a case-control study. J Endod. 2017;43(10):1611-4.

24. Peters LB, Lindeboom JA, Elst ME, Wesselink PR. Prevalence of apical periodontitis relative to endodontic treatment in an adult Dutch population: a repeated cross-sectional study. Oral Surgery, Oral Medicine, Oral Patho, Oral Radiol, and Endodon. 2011;111(4):523-8.

25. Souza LM, Cruz SSd, Gomes-Filho IS, Barreto ML, Passos-Soares JS, Trindade SC, et al. Effect of maternal periodontitis and low birth weight-A case control study. Acta Odontol Scand. 2016;74(1):73-80.

26. Da Silva Barbirato D, Rodrigues MO, Alves JP, de Castro HP, Fogacci MF. Association Between Periodontal Diseases and Adverse Gestation Outcomes: a Review of the Current Literature. Current Oral Health Reports. 2019;6(1):47-59.

CONFLICT OF INTEREST: Authors declare no conflict of interest

GRANT SUPPORT AND FINANCIAL DISCLOSURE: NIL

\section{AUTHOR'S CONTRIBUTION}

Following authors have made substantial contributions to the manuscript as under

Shah H: Conceptualized the study, acquisition, collection, statistical analysis \& interpretation of data, manuscript writing.

Nisar N: Proof Reading and final approval

Butt S: Data collection and editing manuscript

Ali AH: Data collection.

Authors agree to be accountable for all aspects of the work in ensuring that questions related to the accuracy or integrity of any part of the work are appropriately investigated and resolved. 